\title{
Een op de technologische leercurve gebaseerd aandachtsgebiedenbeleid
}

\section{Inleiding}

De economische crisis heeft geleid tot hernieuwde belangstelling voor een actief en selectief industriebeleid. Niet alleen de explosieve stijging van de prijs van ruwe olie en het uit de pas lopen van de Nederlandse loonkostenontwikkeling krijgen de schuld van de economische neergang.

Analyses in de Innovatienota van 1979, het rapport 'Plaats en Toekomst van de Nederlandse Industrie' en het eerste 'Verslag van Werkzaamheden' van de Adviescommissie inzake de Voortgang van het Industriebeleid (1983) (de Commissie Wagner) hebben de schijnwerpers gericht op de verouderde structuur van de Nederlandse industrie. De algemene remedie is het streven naar meer 'kennisintensieve', 'technologisch hoogwaardige' en 'innovatieve' activiteiten. Deze gedachtengang is in principe gerechtvaardigd. Nederland is een volwassen industrieland geworden en moet concurreren met landen die al jaren, al of niet expliciet (vergelijk bijvoorbeeld Frankrijk met WestDuitsland), een selectief industriebeleid voeren. De vraag is echter hoe doelstellingen als 'kennisintensief' en 'technologisch hoogwaardig' te operationaliseren bij de selectie van kansrijke activiteiten. Het gevaar dreigt van een eenzijdig 'witte jassen'-beleid ter bevordering van wetenschappelijk onderzoek, terwijl voorbijgegaan wordt aan de echte technologische zwaktes van de Nederlandse industrie. Het is de verdienste van de Commissie Wagner dat gepoogd is een selectief beleid te formuleren - het aandachtsgebiedenbeleid - waarbij zowel de bestaande Nederlandse comparatieve voordelen als de internationale ontwikkelingen in markten en technologie uitgangspunten vormen. Om tot de keuze van kansrijke activiteiten te komen zijn twee voorstudies gedaan door respectievelijk de Economische faculteit van de Erasmus Universiteit en het Studiecentrum voor Technologie en Beleid (STB) van TNO. Voor de voorstudie uitgaande van de internationale markten wordt verwezen naar de bijdrage van Tettero (1983). In het navolgende zal de studie van STB uitgaande van internationale technologische ontwikkelingen aan de orde komen. Zoals gezegd kan dit gezien worden als een operationalisering van het beleid gericht op de bevordering van kennisintensieve en technologisch geavanceerde industriële produktie. We zijn bij het zoeken naar kansrijke activiteiten niet uitgegaan van research en ontwikkeling uitgaven, universitaire specialisaties, een Delphi-onderzoek onder wetenschappelijke deskundigen, of andere veel gebruikte indicatoren van innovativiteit. We hebben daarentegen geprobeerd nauw aan te sluiten 
bij de manier waarop in de industrie over innovatie als concurrentiemiddel wordt gedacht door uit te gaan van een portfolio-analyse gebaseerd op leercurve-effecten. We moeten met nadruk wijzen op het feit dat deze analyse in de eerste plaats nuttig is voor ondernemingen die de lange termijn strategie aanhangen van concurrentie op basis van technologische voorsprong. Niet voor niets is de methode het eerst ontwikkeld bij General Electric Corporation. Evenzo is deze methode in het kader van industriebeleid vooral van toepassing op die delen van de industrie die concurreren op basis van hun technologische kennis. Aan het slot van dit artikel zullen we in het kort ingaan op de vertaalslag van de lijst van kansrijke activiteiten naar daadwerkelijke initiatieven zonder dat de in Nederland gegroeide taakverdeling tussen overheid en particulier initiatief daarbij verstoord wordt.

\section{Industriebeleid op basis van portfolio-analyse}

Het uitgangspunt van onze studie is geweest dat in het kader van een selectief industriebeleid voor Nederland een analyse gemaakt kan worden vergelijkbaar met de 'Boston Consulting Group' portfolio-analyse die vele grotere bedrijven van hun verschillende industriële activiteiten ('business units') maken. Zoals bekend (zie ook het artikel van Tettero) worden activiteiten hierbij ingedeeld in hoog en laag wat betreft verwachte groei van de betreffende markt en in positief en negatief wat betreft de marktpositie van de eigen onderneming. Afhankelijk van de aard van het bedrijf wordt de marktpositie bepaald door het bestaande marktaandeel of door de technologische voorsprong die men heeft op de concurrentie.

Gegeven het technologische uitgangspunt van onze studie hebben we voor dit laatste gekozen. De resulterende $2 \times 2$ matrix levert een indeling van industriële activiteiten in 4 categorieën op (Figuur 1).

\begin{tabular}{|l|l|l|}
\hline $\begin{array}{l}\text { Troeivoet } \\
\text { van de vraag } \\
\text { voorsprong }\end{array}$ & positief & negatief \\
\hline hoog & 'ster' & 'wild cat' \\
\hline laag & 'melkkoe' & 'dog' \\
\hline
\end{tabular}

\section{Figuur 1}

De portfolio-analyse bij concurrentie op basis van technologische voorsprong.

Scoort een activiteit hoog zowel wat betreft marktgroei als technologische voorsprong dan spreken we van een 'ster'. Is de marktgroei hoog en de technologische voorsprong nog twijfelachtig dan spreken we van een 'wild cat'. Bij een volgroeide markt en gevestigde technologische voorsprong 
maakt de resulterende gunstige positie het mogelijk te spreken van een 'melkkoe' omdat dan uiteraard hoge winsten gerealiseerd kunnen worden. Scoort een activiteit laag op zowel marktgroei als technologische voorsprong dan is de activiteit een 'dog' en in eerste instantie een kandidaat voor spoedige afbouw.

De dynamische analyse die aan deze vorm van ondernemingsplanning ten grondslag ligt is dat uit een grote groep 'wild cats' een beperkt aantal zich tot 'ster' ontwikkelt. Door marktverzadiging groeien sterren op den duur uit tot 'melkkoeien'. Door imitatie van concurrenten verworden melkkoeien tenslotte tot 'dogs'. Om over voldoende melkkoeien te beschikken om een hoge ondernemingswinst te bereiken (c.q. voor een land om een gunstig welvaartsniveau te kunnen bereiken) moeten er voortdurend nieuwe 'sterren' ontwikkeld worden en moet er derhalve ook in 'wild cats' worden geïnvesteerd. De motor van de geschetste dynamiek ligt in de technologische levenscyclus van een industriële activiteit (Figuur 2). Volgens deze levenscyclus wordt de vroege fase van een industriële activiteit gekenmerkt door frequente innovaties aan het produkt, waardoor dit produkt steeds beter zijn beoogde functie gaat vervullen en waardoor de markt groeit. Door de groei in het volume van de produktie neemt vervolgens het aantal procesinnovaties toe.

Naarmate echter de markt verzadigd raakt en de technologie zich uitkristalliseert neemt het aantal innovaties af. De technologische mogelijkheden raken uitgeput. Over het algemeen zullen we 'wild cats' vooral in fase 1 aantreffen, 'sterren' vooral in fase 2 en 'melkkoeien' in fase 3.

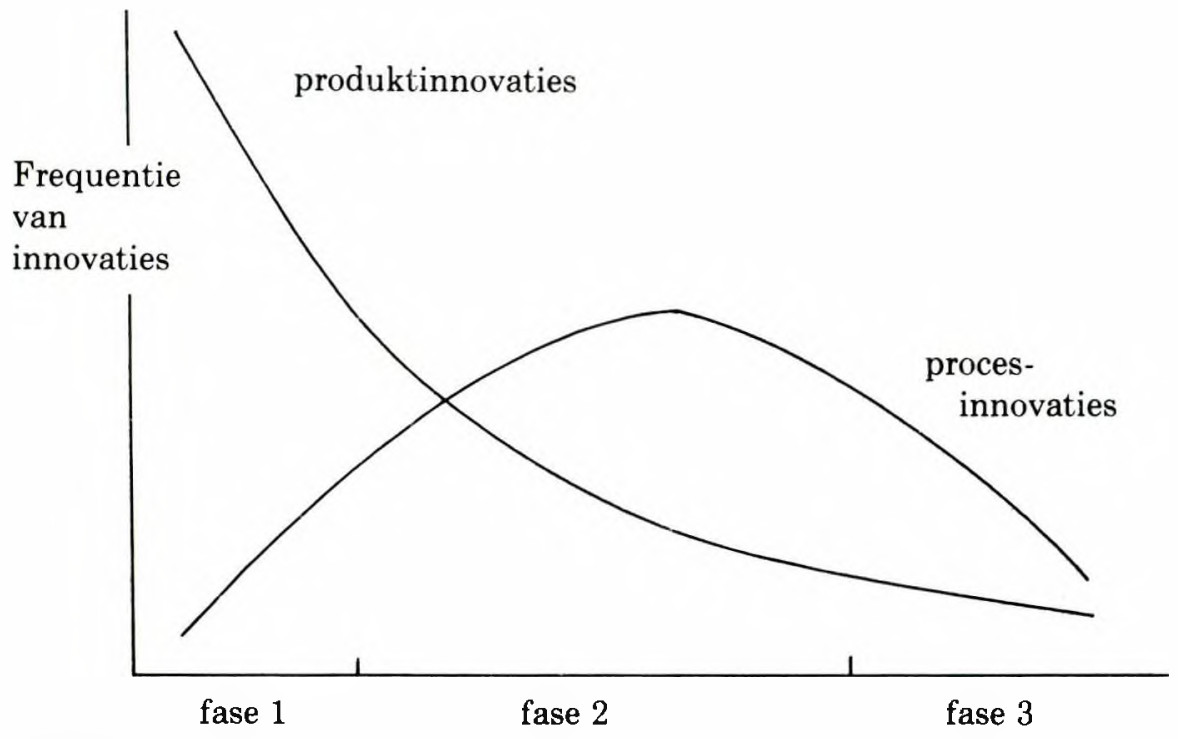

Figuur 2

De technologische levenscyclus van een industriële activiteit.

Het bovenstaande proces kunnen we ook weergeven aan de hand van het verloop van de technologische leercurve. Deze curve geeft het verband aan 
tussen het aantal geproduceerde aantallen en de resultaten van een bepaalde technologie zoals deze in de praktijk meetbaar zijn voor de functievervulling (bijv. rendement van een motor, aantal functies van een computersysteem) en de kosten per geproduceerde eenheid (zie bijv. Abell en Hammond, 1979; blz. 110 en 111). Naarmate de leercurve minder stijl verloopt kunnen we zeggen dat de technologische mogelijkheden uitgeput raken. In de praktijk van de industriële concurrentie betekent dit dat het steeds moeilijker wordt om een voorsprong te behouden op basis van knowhow en technische ervaring. Er komen steeds meer concurrenten, de winstmarge daalt en de activiteit kan niet langer als 'melkkoe' gelden. Steeds geldt dat 'wild cats' en 'sterren' gekenmerkt worden door stijl verlopende leercurve.

Een zeer belangrijk gevolg van het leercurve-effect voor de onderneming en mutatis mutandis voor een actief en selectief industriebeleid is dat voor de producent geldt dat zijn innovativiteit afhangt van het aantal geproduceerde eenheden produkt. Door in een vroeg stadium meer te verkopen dan zijn concurrenten verkrijgt deze ceteris paribus een steeds grotere voorsprong op hen in specifieke know-how, welke resulteert in betere kwaliteit en/of lagere kosten per eenheid produkt. Dit leidt voor de onderneming tot het strategische besluit om de cash flow die gegenereerd wordt door 'melkkoeien' aan te wenden om verliezen te accepteren op 'wild cats'.

Deze financiële bevoordeling is nodig om twee redenen. In de eerste plaats moet het produkt soms worden aangeboden tegen prijzen die niet kostendekkend zijn, om voldoende afzet te genereren teneinde een voorsprong mogelijk te maken op de leercurve. (Deze strategie wordt in de praktijk duidelijk toegepast door de producenten van de opeenvolgende generaties van halfgeleiders.) In de tweede plaats moet er in vele 'wild cats' worden geïnvesteerd terwijl het zeker is dat slechts enkele van deze activiteiten ooit de status van 'ster' zullen bereiken. Om te weten te komen welke activiteiten het wel en welke het niet zullen halen is echter een minimaal niveau van investering noodzakelijk. (De term 'wild cat' is dan ook ontleend aan de olie-exploratie-industrie, waar door de geologische omstandigheden vaak slechts door het doen van een proefboring, de 'wild cat', het duidelijk wordt of er al of niet rendabele hoeveelheden olie in de bodem aanwezig zijn).

\section{Op zoek naar kansrijke activiteiten}

Industriebeleid verschilt van ondernemingsplanning o.a. daarin, dat er niet uitgegaan kan worden van een lijst van bestaande 'business units', die vervolgens getoetst kunnen worden op hun technologische en commerciële vooruitzichten. Er dient meer in het algemeen gezocht te worden naar kansrijke industriële activiteiten waarbij sprake is van een stijle leercurve en een groeiende markt. In tweede instantie volgt dan een toetsing of de stijle leercurve van Nederland een potentiële voorsprong oplevert. Om deze activiteiten op te sporen is een aanzienlijk onderzoek vereist. Als uitgangspunt voor de voorstudie is, gezien de beperkte tijd die beschikbaar was, gekozen voor bestaande studies gepubliceerd in de technologische, bedrijfs- 
kundige, research management en marketing literatuur, alsmede rapporten over recente industriepolitieke keuzeprocessen in andere landen zoals Frankrijk, Zweden en Japan. De internationale consensus t.a.v. verwachte technologische ontwikkelingen bleek hierbij aanzienlijk, zodat achteraf gesteld kan worden dat een - veel langduriger - op primaire bronnen gebaseerde studie waarschijnlijk niet veel meer zou hebben opgeleverd.

Voordat we de in de literatuur gevonden opsomming van perspectief biedende technologische ontwikkeling aan een nader onderzoek onderwerpen lijkt het ons de moeite waard om op te merken dat deze op zich indrukwekkend is. Ondanks de economische crisis is er weinig reden om aan te nemen dat er een gebrek is aan technologische mogelijkheden. Met name op het gebied van de micro-elektronica en de biotechnologie doen zich talrijke belangrijke ontwikkelingen voor. Bovendien wordt onze indruk uit een eerdere studie (Prakke en Tuininga, 1982) bevestigd dat deze in vergelijking met de dominante technologische ontwikkelingen van de jaren vijftig en zestig (bijv. kernenergie, petrochemie, straalvliegtuigen) vaak opvallend kleinschalig zijn. Hoewel automatiseringsontwikkelingen een opvallende rol spelen, treffen we toch ook veel tamelijk fundamentele produktinnovaties aan.

Tijdens het zoekproces bleek dat er duidelijk drie niveaus te onderscheiden zijn waarop technologische ontwikkelingen worden beschreven. Steeds gaat het in wezen om combinaties van technologische vruchtbaarheid enerzijds en perspectief biedende toepassingsgebieden anderzijds. Naar toenemende concretisering van onderzoeksdoel en markt kunnen we de volgende drie niveaus onderscheiden:

\section{Vruchtbare gebieden van industrieel gericht onderzoek.}

Dit zijn algemene, veelal disciplinair gedefinieerde gebieden van industrieel onderzoek en ontwikkeling, die van economisch belang worden geacht, meestal echter op de wat langere termijn. Voorbeelden zijn micro-elektronica, biotechnologie en lasertechnologie. Het opstellen van een dergelijke lijst kan nuttig zijn voor een onderzoekbeleid, maar leidt niet tot een selectie van industriële activiteiten.

\section{Technologische aandachtsgebieden.}

Dit zijn combinaties van vruchtbare onderzoeksgebieden (dikwijls meer dan een) en een zich duidelijk aftekenende maatschappelijke behoefte. In principe zijn deze analoog aan wat in economisch-historisch onderzoek en in de langegolf theorie (zie bijv. Van Duijn, 1981) retrospectief wordt aangeduid met de term 'leading sector' (i.e. in het verleden: de spoorwegen, automobielverkeer, elektrificatie, petrochemie, landbouwmechanisatie, etc.). Verwacht kan worden dat deze ontwikkelingen de trekkers zullen zijn van een structurele heropleving van de economische bedrijvigheid. Op basis van onze verkenning zijn we tot twaalf technologische aandachtsgebieden gekomen, te weten:

1 kantoorsystemen

2 produktiebesturingssystemen

3 consumentenelektronika 
4 telecommunicatiesystemen en media

5 offshore

6 energieproduktie, opslag en distributie

7 energiebesparingsapparatuur

8 industriële biotechnologie

9 agrarische biotechnologie

10 milieutechnologie (incl. afvalverwerking)

11 medische technologie

12 nieuwe materialen, onder te verdelen in nieuw t.a.v.

- constructieve eigenschappen

- chemische eigenschappen, en

- elektrische eigenschappen.

\section{Potentiële kansrijke activiteiten.}

Kansrijke activiteiten definiëren wij als activiteiten binnen technologische aandachtsgebieden die voor 1990 commercialiseerbaar zijn. Omdat het een hachelijke zaak is geïsoleerde technische ontwikkelingen te evalueren en nagenoeg alle op bestaande lijsten voorkomende concretere activiteiten te schikken waren onder technologische aandachtsgebieden, hebben we ons deze beperking opgelegd. De elementen van de lijst met technologische aandachtsgebieden ('leading sectors') vormen derhalve de kopjes van de lijst met kansrijke activiteiten. Deze laatste kunnen ook beschouwd worden als tamelijk concrete produkt-markt combinaties. $\mathrm{Zij}$ komen het meest overeen met de 'business units' uit de portfolio-analyse.

Vergeleken met de eerder genoemde lijst praten we t.a.v. potentiële kansrijke activiteiten over 'ontwikkeling' in plaats van 'onderzoek' en over 'afzetverwachtingen voor 1990' in plaats van over 'groeiende maatschappelijke behoeften'. Voorbeelden zijn facsimile apparatuur (originelen scanners en laser printers), elektronische archivering, software voor patroonherkenning, video-camera's, afvalverwerking, warmte/krachtinstallaties, pijpleidingsystemen, farmaceutische produkten door middel van fermentatieprocessen, biologische pesticiden en composiet plastics. De volledige lijst van 78 potentiële kansrijke activiteiten wordt in de STB-voorstudie (Prakke, 1983) gepresenteerd.

Nadat op basis van de literatuur de drie lijsten waren opgesteld zijn deze ter becommentariëring verstuurd aan een aantal research-coördinatoren van grote Nederlandse industriële bedrijven. Dit resulteerde in een aantal veranderingen in de samenstelling en formulering van de lijsten. De verbeterde versies zijn vervolgens vergezeld van vragenlijsten verstuurd aan vijftig Nederlandse industriële deskundigen. Hierbij werd door de Stichting Toekomstbeeld der Techniek (STT) bemiddeld. STT belegde tevens in samenwerking met de Commissie Wagner een vergadering waarop uitvoerig mondeling commentaar werd geleverd, zowel t.a.v. de samenstelling van de lijst als t.a.v. de strategische toetsing van de activiteiten voor Nederland. De strategische toetsing van de 78 potentiële kansrijke activiteiten voor de Nederlandse situatie gebeurde aan de hand van vragen over de verwantschapsrelatie met bestaande activiteiten in Nederland op basis van kennis (de beschikbaarheid van relevante know-how), produktie (de beschikbaar- 
heid van o.a. produktiecapaciteit, toeleveranciers en geschoold personeel), en afzet (o.a. de geschiktheid van bestaande exportkanalen). Te zamen leverden de scores op deze criteria een beeld van de algemene comparatieve voordelen van Nederland t.a.v. de onderzochte activiteit.

De activiteiten die positief te voorschijn kwamen uit deze toetsing werden opgenomen in de uiteindelijke lijst van hoofdaandachtsgebieden en activiteiten van de Commissie Wagner (aangeduid met een * in tabel 1 bij het artikel van Tettero). Aldus ontstond via een interactief proces, waaraan velerlei deskundigen in de industrie, bij de overheid en bij TNo hun bijdragen hebben geleverd, de uiteindelijke lijst van kansrijke gebieden. Opvallend hierbij was dat er een redelijke mate van consensus bleek uit de vele commentaren en dat zeer positief gereageerd werd op de mogelijkheid langs deze weg een strategische discussie over het Nederlandse aandachtsgebied te kunnen voeren. De kwaliteit van de informatie vervat in de lijst is ons inziens uiteindelijk op een goed niveau gekomen. Op vele gebieden zal het echter nodig zijn het proces van informatieverzameling voort te zetten alvorens tot actie kan worden overgegaan. Dit gebeurt thans in het kader van het aandachtsgebiedenbeleid door middel van zo geheten 'detailstudies' en informeel overleg.

\section{Tot slot}

Enige woorden over de betekenis van de geproduceerde lijst van kansrijke activiteiten zijn hier op hun plaats. Technologische mogelijkheden alléén zullen ons niet uit het dal van de economische crisis naar nieuwe economische groei leiden. Hiertoe is naar onze mening een wisselwerking tussen technische innovatie en structurele sociale innovatie nodig. Technische innovatie lijkt daarbij niet achter te blijven, maar een nieuwe periode van evenwichtige economische groei vereist fundamentele aanpassingen op gebieden zoals de aanbodstructuur van de economie en verwachtingspatronen van economische subjecten. In dit kader is het niet mogelijk om daar in detail op in te gaan. Zeker lijkt wel dat we nu een periode ingaan, waarin de maatschappelijke bereidheid tot het aanvaarden van nieuwe structuren, nieuwe verantwoordelijkheden, nieuwe vormen van coöperatie en in het bijzonder de bereidheid tot experimenteren en het dragen van risico essentieel zullen zijn. In dat kader dient ook de ontwikkeling van een actief aandachtsgebiedenbeleid gezien te worden, waarbij zowel van de kant van ondernemingen en instellingen initiatieven worden genomen.

In aansluiting op het bovenstaande dient er iets gezegd te worden over het gebruik van deze lijst van kansrijke activiteiten. In wezen is dat een oefening in ondernemingsplanning op nationale schaal. De gulden regel daarbij is dat het proces van plannen maken, overleg, toetsing en systematische informatie-inwinning uiteindelijk belangrijker is dan 'het' uiteindelijke plan. Een land als Japan, dat zo vaak ten voorbeeld wordt gehouden op het gebied van industriebeleid, maakt geen betere keuzes van kansrijke activiteiten dan wij. Wel bestaat er in Japan - en daar werd herhaaldelijk de nadruk op gelegd door onze referenten - een systeem van netwerken welke, zonder het belang van deelnemende partijen uit het oog te verliezen, met 
gezamenlijke inspanning in staat zijn ten behoeve van de economische ontwikkeling gebruik te maken van de kansen die de technologie biedt. Er lijkt op de voorhand geen reden te zijn waarom initiatieven tot het vormen van dergelijke netwerken in Nederland zouden moeten falen.

Sinds het publiceren van de lijst van aandachtsgebieden door de Commissie Wagner in januari van dit jaar, zijn reeds 30 afzonderlijke projecten op gang gebracht op initiatief van het departement van Economische Zaken of op initiatief van bedrijven en instellingen. Daaronder zijn detailstudies op het gebied van kunstmest, landbouwwerktuigen en machines voor de verpakking van voedingsmiddelen. Informele overleggroepen zijn gestart op het gebied van biotechnologie en toeleveranties in de automobiel- en in de vliegtuigbouwindustrie. Het zal noodzakelijkerwijs van deze nadere studies en overlegactiviteiten afhangen of inderdaad nieuwe industriële activiteiten tot stand zullen komen. De eerste reactie op de in dit artikel beschreven vorm van actief industriebeleid mag echter bemoedigend genoemd worden en verdient zeker navolging.

\section{Literatuur}

- Adviescommissie inzake de Voortgang van het Industriebeleid, Verslag van werkzaamheden 2. Ministerie van Economische Zaken, Den Haag, 1983.

- Abell, D. F. en Hammond, J. S. Strategic market planning, Prentice-Hall, Englewood Cliffs, 1979.

- Van Duijn, J. J. The long wave in economic life. George Allen \& Urwin, London, 1982.

- Prakke, F. en Tuininga, E. J. 'Technology and economic development; the identification of major technical changes and an analysis of their influence on growth and decline of employment in selected sectors'. Rapport aan FAST-EG, STB-TNO, Apeldoorn, 1982.

- Prakke, F. Toekomstige industriële activiteiten op basis van nieuwe technologische ontwikkelingen. STB-TNO, Apeldoorn, 1983.

- Tettero, J. H. J. P. Positie en perspectieven van Nederland in de wereldhandel voor industriële produkten en diensten. Vakgroep Commerciële Beleidsvorming. Erasmus Universiteit Rotterdam, 1983.

- Utterback, J. M. en Abernathy, W.C. 'Patterns of industrial innovation', Technology Review, juni/juli, 1978. 